\title{
Effect of Polycalcium, a mixture of Polycan and calcium lactate-gluconate in a 1:9 weight ratio, on rats with surgery-induced osteoarthritis
}

\author{
JAE-SUK CHOI ${ }^{1,2^{*}}$, HYUN-SOO SHIN ${ }^{3 *}$, KI YOUNG KIM ${ }^{4}$, SAE KWANG KU ${ }^{5}$, \\ IN SOON CHOI ${ }^{1,6}$ and JOO WAN KIM ${ }^{4}$
}

\begin{abstract}
${ }^{1}$ RIS Center, Industry-Academic Cooperation Foundation, Silla University, Busan 702-701; ${ }^{2}$ Department of Bio-food Materials, Silla University, Busan 617-736; ${ }^{3}$ Namyang Dairy Products Co., Ltd., Gongju 314-914; ${ }^{4}$ Glucan Corporation Research Institute, Marine Biotechnology Center, Busan 702-701;

${ }^{5}$ Department of Anatomy and Histology, College of Oriental Medicine, Daegu Haany University, Gyeongsan 712-715; ${ }^{6}$ Department of Biological Science, Silla University, Busan 702-701, Republic of Korea
\end{abstract}

Received March 24, 2014; Accepted October 6, 2014

DOI: $10.3892 /$ etm.2015.2332

\begin{abstract}
In the present study, the beneficial and synergistic effects of Polycalcium, a mixture of Polycan and calcium (Ca) lactate-gluconate in a 1:9 weight ratio, on a rat model of osteoarthritis (OA) were explored. Polycalcium (50, 100 and $200 \mathrm{mg} / \mathrm{kg}$ ) was administered orally once per day for 28 days from 1 week after the OA-modeling surgery. Diclofenac sodium ( $2 \mathrm{mg} / \mathrm{kg}$ ) was administered as a reference drug. Following the OA surgery, increases in the maximum extension angles, edematous changes in knee and capsule thickness, reductions in chondrocyte proliferation and cartilage glycosaminoglycan (GAG) levels, as well as changes in cartilage degeneration were observed. However, these OA-related symptoms were inhibited after 28 days of continuous oral treatment with Polycalcium. Anti-OA effects, including the induction of chondrocyte proliferation, were detected in the Polycalcium-treated rats and were more favorable compared with those in rats treated with Polycan or Ca lactate-gluconate alone $(100 \mathrm{mg})$. Therefore, a mixture of Polycan and Ca lactate-gluconate was demonstrated to have beneficial synergistic effects on OA.
\end{abstract}

Correspondence to: Dr Joo Wan Kim, Glucan Corporation Research Institute, Marine Biotechnology Center, Baekyangdaero 700, Busan 702-701, Republic of Korea

E-mail:warii@hanmail.net

Professor In Soon Choi, Department of Biological Science, Silla University, Gwaebop-dong, Sasang-gu, Baekyangdaero 700, Busan 702-701, Republic of Korea

E-mail: ischoi@silla.ac.kr

${ }^{*}$ Contributed equally

Key words: calcium, osteoarthritis, Mankin score, $\beta$-glucan, rat

\section{Introduction}

Osteoarthritis $(\mathrm{OA})$ is a degenerative and progressive disease that affects mainly joint cartilage and subchondral bone (1). Conventional drug therapy for OA includes non-opioid analgesics such as paracetamol, non-steroidal anti-inflammatory drugs (NSAIDs), topical and opioid analgesics, and intra-articular steroid injections $(2,3)$. These treatments may be ineffective in certain patients and NSAIDS frequently have serious adverse effects, including gastrointestinal complications $(4,5)$. Thus, drugs with good efficacy and low toxicity are required for the treatment of OA.

Calcium (Ca) salts have anti-inflammatory activities $(6,7)$, and various Ca salts have demonstrated preventive or therapeutic effects on osteoporosis $(8,9)$. Polycan is purified $\beta$-glucan from Aureobasidium pullulans SM-2001, and is comprised mostly of $\beta-1,3 / 1,6$-glucan (10). It has been found that Polycan has anti-osteoporotic effects by inhibiting bone loss and accelerating bone formation $(11,12)$, as well as promoting fracture healing (13) with anti-inflammatory effects $(14,15)$. In addition, the individual effects of Polycan and a $\mathrm{Ca}$ salt in a rat model of OA have been evaluated and revealed beneficial effects following anterior cruciate ligament transection and partial medial meniscectomy, respectively $(16,17)$.

In a previous study, it was found that a mixture of Polycan and $\mathrm{Ca}$ lactate-gluconate in a 1:9 weight ratio, designated Polycalcium, had favorable and synergistic effects on osteoporotic rats compared with two other Polycan/Ca lactate-gluconate mixtures (5:95 and 1:99) (18). In the present study, the beneficial and synergistic effects of Polycalcium on a rat model of OA were compared with the effects of Polycan or Ca lactate-gluconate alone.

\section{Materials and methods}

Animals. A total of 80 Sprague-Dawley specific pathogen-free male rats (6 weeks old upon receipt; Japan SLC, Inc., 
Hamamatsu, Japan) were used following acclimatization for 8 days. Animals were allocated five per polycarbonate cage in a temperature $\left(20-25^{\circ} \mathrm{C}\right)$ and humidity $(30-35 \%)$ controlled room. The light:dark cycle was $12 \mathrm{~h}: 12 \mathrm{~h}$, and commercial feed (Samyang Foods Co., Ltd, Wonju, Korea) and water were supplied ad libitum. The total of the 80 rats were randomly assigned to each of the 8 groups. The study was approved by the Ethics Committee of Daegu Haany University (Gyeongsan, Korea).

Preparation and drug administration. Polycan and Ca lactate-gluconate were supplied by Glucan Corporation (Busan, Korea) as brown and white powders, respectively. Diclofenac sodium was purchased from Wako (Osaka, Japan). All test materials were stored in a refrigerator to protect them from light and moisture. Three different doses (50, 100 and $200 \mathrm{mg} / \mathrm{kg}$ ) of Polycalcium (containing Polycan and calcium lactate-gluconate in a 1:9 weight ratio) were dissolved in distilled water and administered orally once per day for 28 days at $5 \mathrm{ml} / \mathrm{kg}$ from 1 week after OA. In the sham and OA control groups, only $5 \mathrm{ml} / \mathrm{kg}$ distilled water was administered orally from 1 week after the OA-induction surgery. As a reference control, $2 \mathrm{mg} / \mathrm{kg}$ diclofenac sodium (dissolved in saline at a volume of $1 \mathrm{ml} / \mathrm{kg}$ ) was administered subcutaneously once per day for 28 days from 1 week after OA.

Grouping. A total of 80 rats were divided randomly into eight groups as follows: Sham control, OA control, diclofenac-treated, polycan-treated, Ca-LG and polycalcium-treated (with 50, 100 and $200 \mathrm{mg} / \mathrm{kg}$ dose) groups.

Induction of $O A$. Rats were anesthetized with $25 \mathrm{mg} / \mathrm{kg}$ Zoletile intraperitoneally (Zoletile 50; Virbac, Carros, France). The surgical procedure was performed as follows. The OA treatment group underwent open surgery in which anterior cruciate ligament transection and partial medial meniscectomy were conducted via an incision on the medial aspect of the joint capsule of the left knee, anterior to the medial collateral ligament. Following surgery, the incision was closed in two layers. The joint capsule was sutured independently from peripheral tissues using dissolvable 5-0 Vicryl sutures (Ethicon, Inc., Somerville, NJ, USA), and the skin was closed with interrupted silk sutures. This surgery induced OA pathogenesis in the operated knees. The second group of rats underwent a sham surgery in which a similar incision in the joint capsule was made, but anterior cruciate ligament transection and partial medial meniscectomy were not performed.

Changes in body weight. Body weights were measured weekly from the start of treatment until sacrifice using an automatic electronic balance (Precisa Instruments, Dietikon, Switzerland). In addition, body weight gains for 12 weeks after test material treatment were calculated.

Knee thickness measurement. The thickness of the OA-operated left hind knee was measured using an electronic digital caliper (Mitutoyo Corporation, Kawasaki, Japan) and recorded weekly after treatment with test materials. In addition, the knee thickness was measured following joint capsule exposure upon sacrifice to reduce differences from surrounding tissues using the same methods.

Measurement of the maximum extensor angle. OA-operated knees were dissected from the coxofemoral region to the ankle region, leaving the articular capsule intact. Following dissection, the maximum extension angle of each knee was measured as described previously (19), with $0^{\circ}$ corresponding to the maximum possible extension. To minimize bias, all surgeries and measurements of the extension level were performed by the same veterinarian.

Measurement of cartilage glycosaminoglycan (GAG) content. The quantities of cartilage GAGs, namely heparin sulfate, chondroitin sulfate and hyaluronic acid, were measured as described previously (20) using an ultraviolet spectrophotometer (Model 22: Angstrom Advanced Inc., Braintree, MA, USA) at absorbances of 478, 480 and $650 \mathrm{~nm}$, respectively.

Histopathology. The knee joints were sampled with joint capsule preservation and fixed in $10 \%$ neutral-buffered formalin. After 5 days of fixation, the knee joints were decalcified using a decalcifying solution $(24.4 \%$ formic acid and $0.5 \mathrm{~N}$ sodium hydroxide) for 5 days, with exchange of the mixed decalcifying solution once per day over the 5 days. Next, median joints were longitudinally trimmed and embedded in paraffin, sectioned (3-4 $\mu \mathrm{m})$ and stained with Safranin O for cartilage visualization as described previously (21-23). Histological profiles of the knee joints were evaluated using Mankin scoring (24,25), and the thickness of articular cartilage was compared with that of the intact control.

5-Bromo-2'-deoxyuridine (BrdU) uptake measurement. To assess the effects of Polycalcium on the proliferation of cells, proliferating cells were labeled by means of an intraperitoneal injection of BrdU (Sigma, St. Louis, MO, USA). One hour prior to test material treatment (on day 25 of treatment), rats were administered intraperitoneal injections of BrdU at $50 \mathrm{mg} / \mathrm{kg}$ dissolved in saline, and the animals were sacrificed $72 \mathrm{~h}$ later, as described previously (26). BrdU uptake was detected with an anti-BrdU antibody as described by Moore et al (27). Fixed tissues were prepared, embedded in paraffin, and sectioned as described above. Tissues were de-paraffinized through a series of washes with xylene and graded alcohols. Following epitope retrieval by pretreatment with trypsin (Sigma) and $2 \mathrm{~N} \mathrm{HCl}$, as described previously, sections were immunostained $(28,29)$ using primary BrdU antiserum (anti-BrdU monoclonal antibody; VP-B209; Vector Laboratories, Inc., Burlingame, CA, USA), Vectastain Universal Elite ABC kit (PK-6200; Vector Laboratories, Inc.) and DAB Peroxidase Substrate kit (SK-4100; Vector Laboratories, Inc.).

BrdU immunoreactive cell counts were determined as follows: Among 100 chondrocytes, cells accounting for $>10 \%$ of BrdU immunoreactivity were detected in the inner articular membrane and surface articular cartilage of the femur and tibia using an automated digital image analyzer (DMI-300; DMI, Daegu, Korea). The histopathologist was blinded to group distribution during this analysis. 


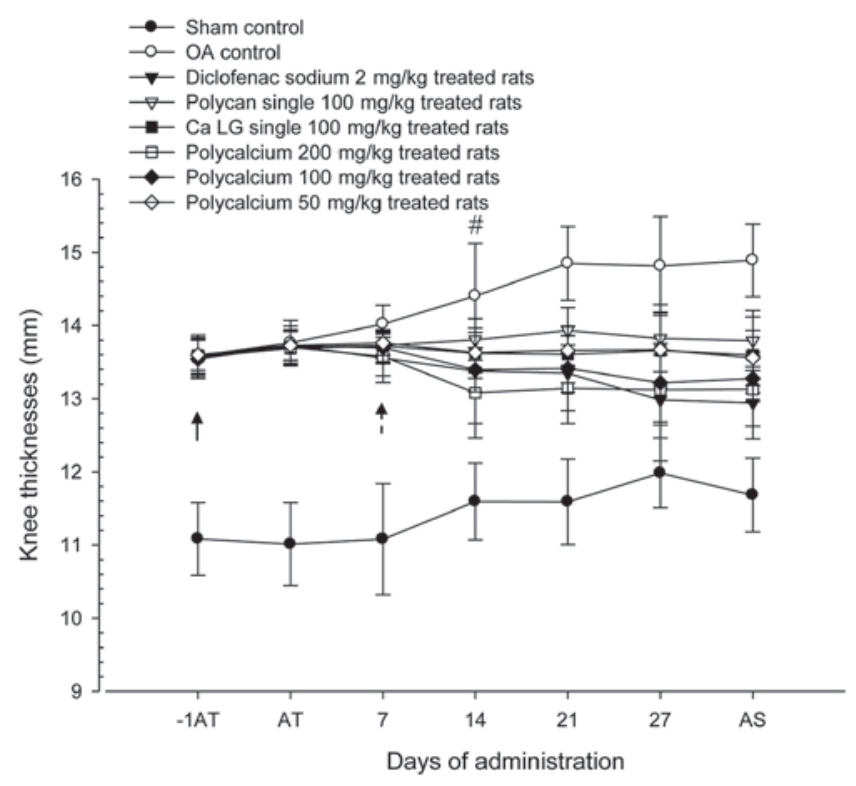

Figure 1. Changes in OA-induced knee thickness during 28 days of continuous oral treatment with test materials in a rat model of OA. Note that significant $(\mathrm{P}<0.01)$ increases in $\mathrm{OA}$-operated knee thickness were detected in the OA control from 1 day prior to test material treatment as compared with the sham control (arrow). However, these increases in OA-induced knee thickness were significantly $(\mathrm{P}<0.01)$ attenuated in polycan $(\# ; \mathrm{P}<0.05$ on day 14), $\mathrm{PC} 100 \mathrm{mg} / \mathrm{kg}, 200 \mathrm{mg} / \mathrm{kg}$, diclofenac-treated groups and were significantly $(\mathrm{P}<0.05)$ attenuated in $\mathrm{PC} 50 \mathrm{mg} / \mathrm{kg}$, Ca LG $100 \mathrm{mg} / \mathrm{kg}$ treated groups from 7 days after the start of treatment as compared with the OA control (dot arrow). Values are expressed as the mean \pm SD of ten rats. OA, osteoarthritis; Ca, calcium; LG, lactate-gluconate; -1AT; 1 day before the start of test material treatment; AT, start of test material treatment; AS, at sacrifice. All animals were fasted overnight prior to OA induction, the start of test material treatment and sacrifice. $\mathrm{P}<0.05$, diclofenac sodium vs. sham control by least-significant differences (LSD) test. $\mathrm{P}<0.05$, Ca LG vs. sham control by LSD test. $\mathrm{P}<0.05$, polycalcium $50 \mathrm{mg} / \mathrm{kg}$ vs. sham control by LSD test.

Statistical analyses. Multiple comparison tests for different dose groups were conducted. Variance homogeneity was examined using the Levene test. If the Levene test showed no significant deviations from variance homogeneity, the data were analyzed using one-way analysis of variance followed by least-significant differences (LSD) multi-comparison tests to determine which pairs of group comparisons were significantly different. When significant deviations from variance homogeneity were observed based on the Levene test, a non-parametric comparison test, the Kruskal-Wallis $\mathrm{H}$ test, was conducted. When a significant difference was observed in the Kruskal-Wallis $\mathrm{H}$ test, the Mann-Whitney U test was conducted to identify specific pairs of group comparisons that differed significantly. Statistical analyses were conducted using SPSS for Windows (Release 14K, SPSS Inc., Chicago, IL, USA). In addition, the percentage changes compared with the OA control were calculated to increase the understanding of the efficacy of test materials, and the percentage changes between sham and OA control were calculated to determine the induction status of OA.

\section{Results}

Changes in body weight. No significant changes in body weight were detected in test material-treated groups compared with the OA controls (data not shown).
Table I. Knee thickness after joint capsule exposure and maximum extensor angles detected at sacrifice after 28 days of continuous oral treatment with test materials in OA rats.

\begin{tabular}{lcc}
\hline Groups & $\begin{array}{c}\text { Knee thickness } \\
(\mathrm{mm})\end{array}$ & $\begin{array}{c}\text { Maximum extensor } \\
\text { angle }\left(^{\circ}\right)\end{array}$ \\
\hline $\begin{array}{l}\text { Controls } \\
\text { Sham }\end{array}$ & $7.85 \pm 0.29$ & $29.80 \pm 2.66$ \\
OA & $9.26 \pm 0.37^{\mathrm{a}}$ & $57.60 \pm 4.25^{\mathrm{a}}$ \\
Diclofenac & $8.83 \pm 0.42^{\mathrm{a}, \mathrm{b}}$ & $45.90 \pm 6.64^{\mathrm{a}, \mathrm{b}}$ \\
Polycan alone & $8.94 \pm 0.25^{\mathrm{a}, \mathrm{c}}$ & $49.40 \pm 4.03^{\mathrm{a}, \mathrm{b}}$ \\
Ca LG alone & $8.85 \pm 0.32^{\mathrm{a}, \mathrm{b}}$ & $47.70 \pm 3.06^{\mathrm{a}, \mathrm{b}}$ \\
Polycalcium & & \\
$200 \mathrm{mg} / \mathrm{kg}$ & $8.67 \pm 0.36^{\mathrm{a}, \mathrm{b}}$ & $38.30 \pm 5.29^{\mathrm{a}, \mathrm{b}}$ \\
$100 \mathrm{mg} / \mathrm{kg}$ & $8.73 \pm 0.34^{\mathrm{a}, \mathrm{b}}$ & $40.30 \pm 4.47^{\mathrm{a}, \mathrm{b}}$ \\
$50 \mathrm{mg} / \mathrm{kg}$ & $8.85 \pm 0.28^{\mathrm{a}, \mathrm{b}}$ & $46.30 \pm 6.46^{\mathrm{a}, \mathrm{b}}$ \\
\hline
\end{tabular}

Values are expressed as means $\pm \mathrm{SD}$ of 10 rats. OA, osteoarthritis; $\mathrm{Ca}$, calcium; LG, lactate-gluconate. Diclofenac sodium, Polycan and Ca LG were administered at 2, 100 and $100 \mathrm{mg} / \mathrm{kg}$, respectively. ${ }^{\mathrm{a}} \mathrm{P}<0.01$ vs. with sham control using the least-significant differences (LSD) test. ${ }^{b} \mathrm{P}<0.01$ and ${ }^{\mathrm{C}} \mathrm{P}<0.05$ vs. the $\mathrm{OA}$ control using the LSD test.

Changes in knee thickness prior to articular capsule exposure. Significant $(\mathrm{P}<0.01)$ increases in OA-operated knee thickness were detected in the OA controls compared with the sham controls from the initial treatment day until day 28. However, the OA-induced increases in induced knee thickness were significantly $(\mathrm{P}<0.01$ or $\mathrm{P}<0.05)$ attenuated from 7 days after treatment with test materials, including diclofenac sodium. The Polycalcium $(50 \mathrm{mg} / \mathrm{kg})$-treated group exhibited an inhibitory effect of the OA-induced increase in knee thickness similar to that in the Ca lactate-gluconate-treated group. The least significant reversal in knee thickness increase was observed in the Polycan-treated group (Fig. 1).

The knee thickness of the OA control was increased by $27.45 \%$ compared with that of the sham control. Reductions in knee thickness of 13.08, 7.36, 8.69, 11.82, 10.83 and 8.95\% were observed following treatment with diclofenac sodium, Polycan alone, Ca lactate-gluconate alone and Polycalcium $(50,100$ and $200 \mathrm{mg} / \mathrm{kg})$, respectively, compared with the knee thickness in the OA control group.

Changes in knee thickness following capsule exposure. The thickness of the OA-operated knees following joint capsule exposure was significantly $(\mathrm{P}<0.01)$ increased in all OA-induced groups compared with the sham control. However, the OA-induced increases in knee thickness following joint capsule exposure were significantly $(\mathrm{P}<0.01$ or $\mathrm{P}<0.05)$ reversed in all test material-treated groups. The Polycalcium $(50 \mathrm{mg} / \mathrm{kg}$ )-treated group exhibited a reversal effect on the increases in knee thickness similar to those of Polycan alone and $\mathrm{Ca}$ lactate-gluconate alone. Joint capsule exposure to Polycan alone exhibited the least significant reversal of the increase in knee thickness (Table I). 
Table II. Knee cartilage GAG contents at sacrifice after 28 days of continuous oral treatment with test materials in OA rats.

Cartilage GAGs contents (mg/g defatted tissues)

\begin{tabular}{|c|c|c|c|}
\hline \multirow[b]{2}{*}{ Groups } & \\
\hline & Chondroitin sulfate & Heparan sulfate & Hyaluronic acid \\
\hline \multicolumn{4}{|l|}{ Controls } \\
\hline Sham & $77.28 \pm 10.67$ & $224.59 \pm 32.68$ & $2.35 \pm 0.41$ \\
\hline $\mathrm{OA}$ & $45.77 \pm 10.47^{\mathrm{a}}$ & $133.12 \pm 26.26^{\mathrm{a}}$ & $1.36 \pm 0.33^{\mathrm{e}}$ \\
\hline Diclofenac & $57.19 \pm 9.04^{\mathrm{a}, \mathrm{d}}$ & $164.56 \pm 20.38^{\mathrm{a}, \mathrm{c}}$ & $1.69 \pm 0.20^{\mathrm{e}, \mathrm{h}}$ \\
\hline Polycan alone & $56.42 \pm 10.17^{\mathrm{a}, \mathrm{d}}$ & $163.60 \pm 14.81^{\mathrm{a}, \mathrm{c}}$ & $1.64 \pm 0.17^{\mathrm{e}, \mathrm{h}}$ \\
\hline Ca LG alone & $58.96 \pm 14.92^{\mathrm{a}, \mathrm{d}}$ & $173.35 \pm 15.26^{\mathrm{a}, \mathrm{c}}$ & $1.78 \pm 0.28^{\mathrm{e}, \mathrm{h}}$ \\
\hline \multicolumn{4}{|l|}{ Polycalcium } \\
\hline $200 \mathrm{mg} / \mathrm{kg}$ & $66.08 \pm 12.93^{\mathrm{b}, \mathrm{c}}$ & $195.51 \pm 22.36^{\mathrm{a}, \mathrm{c}}$ & $1.97 \pm 0.23^{\mathrm{f}, \mathrm{g}}$ \\
\hline $100 \mathrm{mg} / \mathrm{kg}$ & $63.12 \pm 12.34^{\mathrm{a}, \mathrm{c}}$ & $183.05 \pm 17.69^{\mathrm{a}, \mathrm{c}}$ & $1.89 \pm 0.16^{\mathrm{e}, \mathrm{g}}$ \\
\hline $50 \mathrm{mg} / \mathrm{kg}$ & $58.23 \pm 7.67^{\mathrm{a}, \mathrm{d}}$ & $174.16 \pm 19.89^{\mathrm{a}, \mathrm{c}}$ & $1.78 \pm 0.20^{\mathrm{e}, \mathrm{g}}$ \\
\hline
\end{tabular}

Values are expressed as means \pm SD of 10 rats. OA, osteoarthritis; Ca, calcium; LG, lactate-gluconate; GAGs, glycosaminoglycans. Diclofenac sodium, Polycan and Ca LG were administered at 2,100 and $100 \mathrm{mg} / \mathrm{kg}$, respectively. ${ }^{\mathrm{a}} \mathrm{P}<0.01$ and ${ }^{\mathrm{b}} \mathrm{P}<0.05$ vs. the sham control using the least-significant differences (LSD) test. ${ }^{c} \mathrm{P}<0.01$ and ${ }^{\mathrm{d}} \mathrm{P}<0.05$ vs. the $\mathrm{OA}$ control using the LSD test. ${ }^{\mathrm{e}} \mathrm{P}<0.01$ and ${ }^{\mathrm{f}} \mathrm{P}<0.05$ vs. the sham control using the Mann-Whitney $\mathrm{U}(\mathrm{MW})$ test. ${ }^{\mathrm{g}} \mathrm{P}<0.01$ and ${ }^{\mathrm{h}} \mathrm{P}<0.05$ vs. the $\mathrm{OA}$ control using the MW test.

Knee thickness following joint capsule exposure in the OA control was increased by $17.96 \%$ compared with that in the sham control. Reductions of 4.69, 3.42, 4.43, 6.40, 5.77 and $4.45 \%$ were observed following treatment with diclofenac sodium, Polycan alone, $\mathrm{Ca}$ lactate-gluconate alone and Polycalcium (50, 100 and $200 \mathrm{mg} / \mathrm{kg}$ ), respectively, compared with the knee thickness in the OA control group.

Changes in knee maximum extension angles. The maximum extensor angle of the knee was significantly $(\mathrm{P}<0.01)$ increased in the OA control as compared with that in the sham control. However, this angle were significantly $(\mathrm{P}<0.01)$ decreased in all test material-treated groups as compared with that in the OA control. The Polycalcium (50 mg/kg)-treated group exhibited an inhibitory effect on the maximum extensor angle increases similar to that in the group treated with $\mathrm{Ca}$ lactate-gluconate alone. Polycan alone resulted in the least significant reduction in the extensor angle (Table I).

The maximum extensor angle of the knee in the OA group was increased by $93.29 \%$ compared with that in the sham control. Reductions of 20.31, 14.14, 17.19, 33.51, 30.03 and $19.62 \%$ were observed following treatment with diclofenac sodium, Polycan alone, Ca lactate-gluconate alone, and Polycalcium (50, 100 and $200 \mathrm{mg} / \mathrm{kg}$ ), respectively, compared with the maximum extensor angle in the OA control group.

Changes in cartilage GAG contents. The levels of GAGs in the knee cartilage were significantly $(\mathrm{P}<0.01)$ decreased in the OA control as compared with those in the sham control. However, cartilage GAG contents were significantly $(\mathrm{P}<0.01$ or $\mathrm{P}<0.05)$ higher in all test material-treated groups compared with those in the OA control. The Polycalcium $(50 \mathrm{mg} / \mathrm{kg})$-treated group exhibited an attenuation effect on the reductions in cartilage GAG content similar to that in the group treated with Ca lactate-gluconate alone. Polycan alone resulted in the least significant increase in GAG content (Table II).

The cartilage chondroitin sulfate content of the knee in the OA control was decreased by $40.77 \%$ compared with that in the sham control. Increases of 24.94, 23.28, 28.81, 44.37, 37.91 and $27.22 \%$ relative to the content in the OA control were observed following treatment with diclofenac sodium, Polycan alone, Ca lactate-gluconate alone and Polycalcium (50, 100 and $200 \mathrm{mg} / \mathrm{kg}$ ), respectively.

The knee cartilage content of heparan sulfate in the OA control was decreased by $40.72 \%$ compared with that in the sham control. However, increases of 23.61, 22.89, 30.22, 46.86, 37.50 and $30.83 \%$ relative to those in the OA control were observed following treatment with diclofenac sodium, Polycan alone, Ca lactate-gluconate alone, and Polycalcium (50, 100 and $200 \mathrm{mg} / \mathrm{kg}$ ), respectively.

The knee cartilage content of hyaluronic acid in the OA control was increased by $41.94 \%$ compared with that in the sham control. Increases of $23.80,20.43,30.18,44.54,38.17$ and $30.47 \%$ relative to those in the OA control, were observed following treatment with diclofenac sodium, Polycan alone, Ca lactate-gluconate alone and Polycalcium (50, 100 and $200 \mathrm{mg} / \mathrm{kg}$ ), respectively.

Changes in the Mankin score. Various degrees of articular cartilage surface damage, hypocellularity, clones and Safranin O staining intensity were detected in the OA-induced groups; the total Mankin scores for the tibia and femur of the OA control were significantly $(\mathrm{P}<0.01)$ increased compared with those of the sham control. However, the individual scores varied in all tested groups, and the total Mankin scores in both the tibia and femur of all test material-treated groups were significantly $(\mathrm{P}<0.01)$ decreased compared with those in the OA control. The Polycalcium $(50 \mathrm{mg} / \mathrm{kg})$-treated group demonstrated a reversal of cartilage damage based on 
Table III. Mankin scores detected in the femur at sacrifice after 28 days of continuous oral treatment with test materials in OA rats.

\begin{tabular}{|c|c|c|c|c|c|}
\hline Groups & Surface & Hypocellularity & Clones & Safranin O & Totals $^{\mathrm{a}}$ \\
\hline \multicolumn{6}{|l|}{ Controls } \\
\hline Sham & $0.20 \pm 0.42$ & $0.20 \pm 0.42$ & $0.00 \pm 0.00$ & $0.40 \pm 0.52$ & $0.80 \pm 0.79$ \\
\hline $\mathrm{OA}$ & $2.60 \pm 0.52^{\mathrm{b}}$ & $2.10 \pm 0.88^{\mathrm{e}}$ & $2.40 \pm 0.70^{\mathrm{e}}$ & $2.60 \pm 0.52^{\mathrm{e}}$ & $9.70 \pm 1.42^{\mathrm{e}}$ \\
\hline Diclofenac & $1.60 \pm 0.52^{\mathrm{b}, \mathrm{d}}$ & $1.50 \pm 0.53^{\mathrm{e}}$ & $1.10 \pm 0.74^{\mathrm{e}, \mathrm{g}}$ & $1.40 \pm 0.70^{\mathrm{e}, \mathrm{g}}$ & $5.60 \pm 1.84^{\mathrm{e}, \mathrm{g}}$ \\
\hline Polycan single & $1.40 \pm 0.52^{\mathrm{b}, \mathrm{d}}$ & $1.60 \pm 0.70^{\mathrm{e}}$ & $1.80 \pm 0.79^{\mathrm{e}}$ & $1.50 \pm 0.53^{\mathrm{e}, \mathrm{g}}$ & $6.30 \pm 1.64^{\mathrm{e}, \mathrm{g}}$ \\
\hline Ca LG single & $1.30 \pm 0.82^{\mathrm{b}, \mathrm{d}}$ & $1.40 \pm 0.97^{\mathrm{e}}$ & $1.20 \pm 0.63^{\mathrm{e}, \mathrm{g}}$ & $1.40 \pm 0.52^{\mathrm{e}, \mathrm{g}}$ & $5.30 \pm 2.31^{\mathrm{e}, \mathrm{g}}$ \\
\hline \multicolumn{6}{|l|}{ Polycalcium } \\
\hline $200 \mathrm{mg} / \mathrm{kg}$ & $0.90 \pm 0.88^{\mathrm{c}, \mathrm{d}}$ & $0.70 \pm 0.67^{\mathrm{g}}$ & $0.80 \pm 0.79^{f, g}$ & $0.30 \pm 0.48^{\mathrm{g}}$ & $2.70 \pm 2.50^{\mathrm{g}}$ \\
\hline $100 \mathrm{mg} / \mathrm{kg}$ & $1.00 \pm 0.82^{\mathrm{b}, \mathrm{d}}$ & $0.80 \pm 0.42^{\mathrm{f}, \mathrm{g}}$ & $0.80 \pm 0.79^{\mathrm{e}, \mathrm{g}}$ & $0.90 \pm 0.32^{\mathrm{g}}$ & $3.50 \pm 1.78^{\mathrm{e}, \mathrm{g}}$ \\
\hline $50 \mathrm{mg} / \mathrm{kg}$ & $1.50 \pm 0.71^{\mathrm{b}, \mathrm{d}}$ & $0.80 \pm 0.63^{\mathrm{g}}$ & $1.40 \pm 0.52^{\mathrm{e}, \mathrm{g}}$ & $1.30 \pm 0.48^{\mathrm{e}, \mathrm{g}}$ & $5.00 \pm 1.56^{\mathrm{e}, \mathrm{g}}$ \\
\hline
\end{tabular}

Values are expressed as mean \pm SD scores of 10 rats. OA, osteoarthritis; Ca, calcium; LG, lactate-gluconate. Diclofenac sodium, Polycan and Ca LG were administered at 2, 100 and $100 \mathrm{mg} / \mathrm{kg}$, respectively. ${ }^{\mathrm{a} T o t a l s}$ indicate Mankin scores (maximum, 12 ). ${ }^{\mathrm{b}} \mathrm{P}<0.01 \mathrm{and}{ }^{\mathrm{c}} \mathrm{P}<0.05 \mathrm{vs}$. the sham control using the least-significant differences (LSD) test. ${ }^{\mathrm{d}} \mathrm{P}<0.01$ vs. the $\mathrm{OA}$ control using the LSD test. ${ }^{\mathrm{e}} \mathrm{P}<0.01$ and ${ }^{\mathrm{f}} \mathrm{P}<0.05$ vs. the sham control using the Mann-Whitney U (MW) test. ${ }^{\mathrm{g}} \mathrm{P}<0.01$ vs. the OA control using the Mann-Whitney U (MW) test.

Table IV. Mankin scores detected in tibia at sacrifice after 28 days continuous oral treatment of test materials in OA rats.

\begin{tabular}{|c|c|c|c|c|c|}
\hline Groups & Surface & Hypocellularity & Clones & Safranin O & Totals $^{\mathrm{a}}$ \\
\hline \multicolumn{6}{|l|}{ Controls } \\
\hline Sham & $0.20 \pm 0.42$ & $0.30 \pm 0.67$ & $0.10 \pm 0.32$ & $0.10 \pm 0.32$ & $0.70 \pm 1.06$ \\
\hline $\mathrm{OA}$ & $2.50 \pm 0.71^{\mathrm{b}}$ & $2.40 \pm 0.70^{\mathrm{b}}$ & $2.30 \pm 0.48^{\mathrm{e}}$ & $2.40 \pm 0.70^{\mathrm{e}}$ & $9.60 \pm 2.12^{\mathrm{e}}$ \\
\hline Diclofenac & $1.90 \pm 0.88^{b}$ & $1.30 \pm 0.67^{\mathrm{b}, \mathrm{d}}$ & $0.90 \pm 0.57^{\mathrm{e}, \mathrm{g}}$ & $1.50 \pm 0.85^{\mathrm{e}, \mathrm{h}}$ & $5.60 \pm 2.55^{\mathrm{e}, \mathrm{g}}$ \\
\hline Polycan single & $1.20 \pm 0.63^{\mathrm{b}, \mathrm{d}}$ & $1.20 \pm 0.92^{\mathrm{c}, \mathrm{d}}$ & $1.50 \pm 0.71^{\mathrm{e}, \mathrm{h}}$ & $1.60 \pm 0.70^{\mathrm{e}, \mathrm{h}}$ & $5.50 \pm 2.55^{\mathrm{e}, \mathrm{g}}$ \\
\hline Ca LG single & $1.20 \pm 1.03^{\mathrm{b}, \mathrm{d}}$ & $1.10 \pm 0.88^{\mathrm{c}, \mathrm{d}}$ & $0.90 \pm 0.88^{\mathrm{f}, \mathrm{g}}$ & $1.40 \pm 1.07^{\mathrm{e}, \mathrm{h}}$ & $4.60 \pm 3.53^{\mathrm{e}, \mathrm{g}}$ \\
\hline \multicolumn{6}{|l|}{ Polycalcium } \\
\hline $200 \mathrm{mg} / \mathrm{kg}$ & $0.60 \pm 0.70^{\mathrm{d}}$ & $0.40 \pm 0.70^{\mathrm{d}}$ & $0.20 \pm 0.42^{\mathrm{g}}$ & $0.70 \pm 0.48^{\mathrm{f}, \mathrm{g}}$ & $1.90 \pm 1.79^{\mathrm{g}}$ \\
\hline $100 \mathrm{mg} / \mathrm{kg}$ & $0.80 \pm 0.79^{\mathrm{d}}$ & $0.90 \pm 0.88^{\mathrm{d}}$ & $0.40 \pm 0.52^{\mathrm{g}}$ & $1.00 \pm 0.94^{\mathrm{f}, \mathrm{g}}$ & $3.10 \pm 2.81^{\mathrm{f}, \mathrm{g}}$ \\
\hline $50 \mathrm{mg} / \mathrm{kg}$ & $1.50 \pm 0.97^{\mathrm{b}, \mathrm{d}}$ & $0.90 \pm 1.10^{\mathrm{d}}$ & $1.20 \pm 0.92^{\mathrm{e}, \mathrm{g}}$ & $1.10 \pm 0.74^{\mathrm{e}, \mathrm{g}}$ & $4.70 \pm 3.20^{\mathrm{e}, \mathrm{g}}$ \\
\hline
\end{tabular}

Values are expressed as means \pm SD scores of 10 rats. OA, osteoarthritis; Ca, calcium; LG, lactate-gluconate. Diclofenac sodium, Polycan and Ca LG were administered at 2, 100 and $100 \mathrm{mg} / \mathrm{kg}$, respectively. ${ }^{\mathrm{a}}$ Totals indicate Mankin scores (maximum, 12 ). ${ }^{\mathrm{b}} \mathrm{P}<0.01$ and ${ }^{\mathrm{c}} \mathrm{P}<0.05 \mathrm{vs}$. the sham control using the least-significant differences (LSD) test. ${ }^{d} \mathrm{P}<0.01$ vs. the OA control using the LSD test. ${ }^{e} \mathrm{P}<0.01$ and ${ }^{\mathrm{f}} \mathrm{P}<0.05$ vs. the sham control using the Mann-Whitney $\mathrm{U}(\mathrm{MW})$ test. ${ }^{\mathrm{g}} \mathrm{P}<0.01$ and ${ }^{\mathrm{h}} \mathrm{P}<0.05$ vs. the OA control using the MW test.

the Mankin score similar to that in the group treated with $\mathrm{Ca}$ lactate-gluconate alone. Polycan alone resulted in the least significant decrease in Mankin score (Tables III and IV; Fig. 2).

The total Mankin scores of the articular cartilage of the femur in the OA control group were increased by $1,112.50 \%$ compared with those in the sham control group. Reductions of 42.27, 35.05, 45.36, 72.16, 63.92 and $48.45 \%$ were observed after treatment with diclofenac sodium, Polycan alone, Ca lactate-gluconate alone and Polycalcium (50, 100 and $200 \mathrm{mg} / \mathrm{kg}$ ), respectively, compared with the total Mankin scores of the OA control group.

The total Mankin scores of induced tibia articular cartilages in the OA control were increased by $1,271.43 \%$ compared with those in the sham control. However, reductions of 41.67, 42.71, 52.08, 80.21, 67.71 and $51.04 \%$ were observed following treatment with diclofenac sodium, Polycan alone, Ca lactate-gluconate alone and Polycalcium (200, 100 and $50 \mathrm{mg} / \mathrm{kg}$ ), respectively, compared with the total Mankin scores in the OA control group.

Changes in articular cartilage thickness. Significant $(\mathrm{P}<0.01)$ reductions in articular cartilage thickness were detected in the OA control compared with those in the sham control in both the tibia and femur. However, these reductions in cartilage thickness in the tibia and femur were significantly inhibited by all test materials. The Polycalcium $(50 \mathrm{mg} / \mathrm{kg}$ )-treated group demonstrated inhibitory effects on the reductions in articular 
Table V. Histomorphometrical scores detected at sacrifice after 28 days continuous oral treatment of test materials in OA rats.

\begin{tabular}{|c|c|c|}
\hline \multirow[b]{2}{*}{ Groups } & \multicolumn{2}{|c|}{ Thickness of articular cartilage $(\mu \mathrm{m})$} \\
\hline & Femur & Tibia \\
\hline \multicolumn{3}{|l|}{ Controls } \\
\hline Sham & $703.29 \pm 96.20$ & $962.58 \pm 119.30$ \\
\hline $\mathrm{OA}$ & $259.34 \pm 54.14^{\mathrm{a}}$ & $380.38 \pm 120.17^{\mathrm{a}}$ \\
\hline Diclofenac & $336.46 \pm 45.30^{\mathrm{a}}$ & $485.19 \pm 70.07^{\mathrm{a}, \mathrm{d}}$ \\
\hline Polycan alone & $426.19 \pm 87.28^{\mathrm{a}, \mathrm{c}}$ & $595.24 \pm 96.73^{\mathrm{a}, \mathrm{c}}$ \\
\hline Ca LG alone & $505.66 \pm 133.03^{\mathrm{a}, \mathrm{c}}$ & $684.20 \pm 149.07^{\mathrm{a}, \mathrm{c}}$ \\
\hline \multicolumn{3}{|l|}{ Polycalcium } \\
\hline $200 \mathrm{mg} / \mathrm{kg}$ & $620.82 \pm 112.59^{b, c}$ & $844.02 \pm 130.13^{\mathrm{b}, \mathrm{c}}$ \\
\hline $100 \mathrm{mg} / \mathrm{kg}$ & $588.41 \pm 79.31^{\mathrm{a}, \mathrm{c}}$ & $758.48 \pm 105.01^{\mathrm{a}, \mathrm{c}}$ \\
\hline $50 \mathrm{mg} / \mathrm{kg}$ & $508.78 \pm 62.95^{\mathrm{a}, \mathrm{c}}$ & $686.56 \pm 124.70^{\mathrm{a}, \mathrm{c}}$ \\
\hline
\end{tabular}

Table VI. BrdU-immunoreactive cell numbers detected at sacrifice after 28 days of continuous oral treatment of test materials in $\mathrm{OA}$ rats.

\begin{tabular}{|c|c|c|c|}
\hline \multirow[b]{2}{*}{ Groups } & \multicolumn{3}{|c|}{ Number of BrdU-immunoreactive cells (\%) } \\
\hline & Femur & Tibia & Inner articular membrane \\
\hline \multicolumn{4}{|l|}{ Controls } \\
\hline Sham & $18.70 \pm 2.71$ & $23.60 \pm 4.17$ & $55.30 \pm 13.74$ \\
\hline $\mathrm{OA}$ & $3.80 \pm 3.01^{\mathrm{a}}$ & $5.20 \pm 2.44^{\mathrm{c}}$ & $14.30 \pm 5.08^{c}$ \\
\hline Diclofenac & $3.90 \pm 2.96^{\mathrm{a}}$ & $5.30 \pm 2.31^{\mathrm{c}}$ & $14.40 \pm 6.00^{\mathrm{c}}$ \\
\hline Polycan single & $7.20 \pm 2.49^{\mathrm{a}, \mathrm{b}}$ & $8.80 \pm 1.32^{\mathrm{c}, \mathrm{e}}$ & $28.00 \pm 4.29^{\mathrm{c}, \mathrm{e}}$ \\
\hline Ca LG single & $9.50 \pm 1.58^{\mathrm{a}, \mathrm{b}}$ & $11.00 \pm 1.63^{\mathrm{c}, \mathrm{e}}$ & $31.70 \pm 7.60^{\mathrm{c}, \mathrm{e}}$ \\
\hline \multicolumn{4}{|l|}{ Polycalcium } \\
\hline $200 \mathrm{mg} / \mathrm{kg}$ & $17.80 \pm 2.82^{\mathrm{b}}$ & $26.70 \pm 5.74^{\mathrm{e}}$ & $51.70 \pm 9.59^{\mathrm{e}}$ \\
\hline $100 \mathrm{mg} / \mathrm{kg}$ & $13.70 \pm 3.27^{\mathrm{a}, \mathrm{b}}$ & $23.20 \pm 3.88^{\mathrm{e}}$ & $44.39 \pm 9.39^{\mathrm{d}, \mathrm{e}}$ \\
\hline $50 \mathrm{mg} / \mathrm{kg}$ & $10.80 \pm 2.10^{\mathrm{a}, \mathrm{b}}$ & $12.90 \pm 3.67^{\mathrm{c}, \mathrm{e}}$ & $32.90 \pm 5.38^{\mathrm{c}, \mathrm{e}}$ \\
\hline
\end{tabular}

cartilage thickness that were similar to those observed in the Ca lactate-gluconate group. Polycan alone exhibited the least significant increases in articular cartilage thickness (Table V, Fig. 2).

In the OA control group, the articular cartilage thickness of the femur was decreased by $63.13 \%$ compared with that in the sham control group. Increases of 29.74, 64.34, 94.98, 139.39, 126.89 and $96.18 \%$ were observed following treatment with diclofenac sodium, Polycan alone, Ca lactate-gluconate alone and Polycalcium (50, 100 and $200 \mathrm{mg} / \mathrm{kg})$, respectively, compared with the articular cartilage thickness in the OA control group.

The articular cartilage thickness of the tibia in the OA control group was found to be decreased by $60.48 \%$ compared with that in the sham control group. However, increases in articular cartilage thickness of 27.55, 56.48, 79.87, 121.89, 99.40 and $80.49 \%$ were observed following treatment with diclofenac sodium, Polycan alone, Ca lactate-gluconate alone and Polycalcium (50, 100 and $200 \mathrm{mg} / \mathrm{kg}$ ), respectively, compared with the articular cartilage thickness in the OA control. 


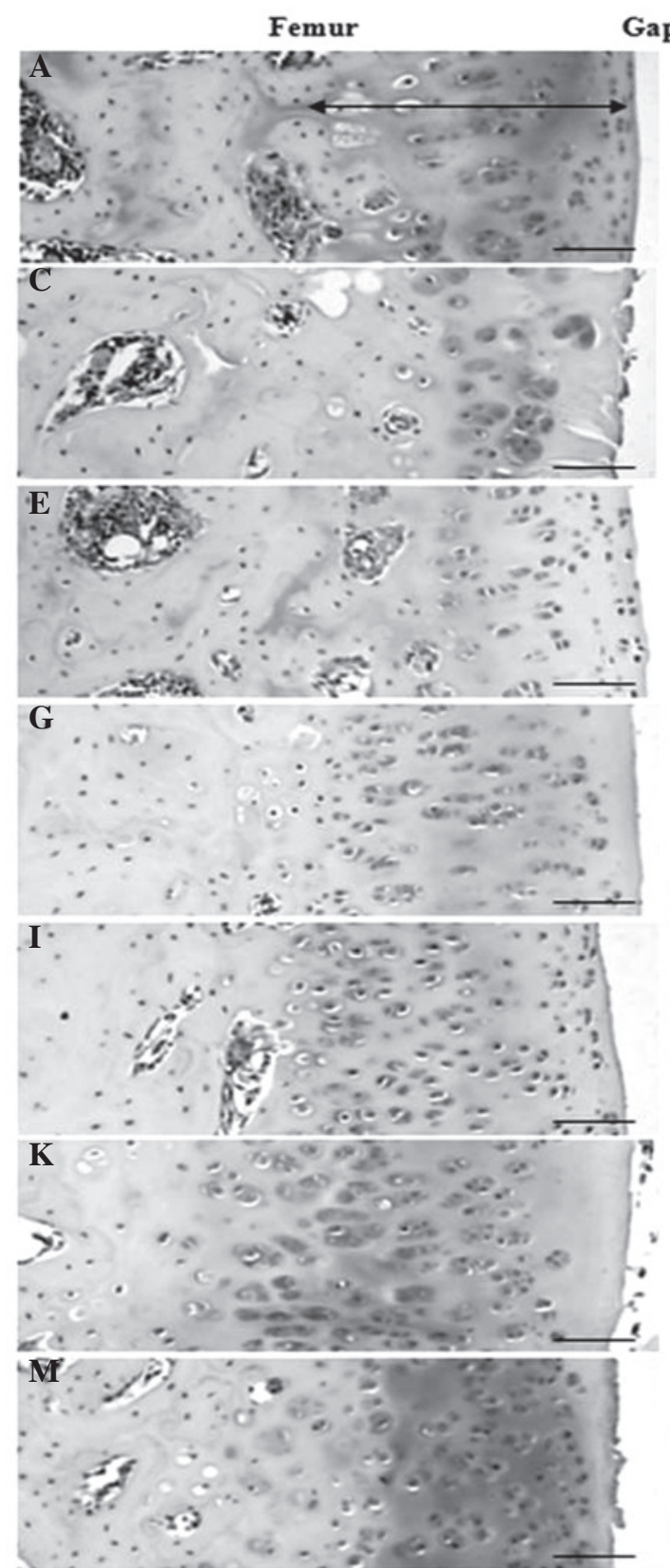

Gaps

Tibia
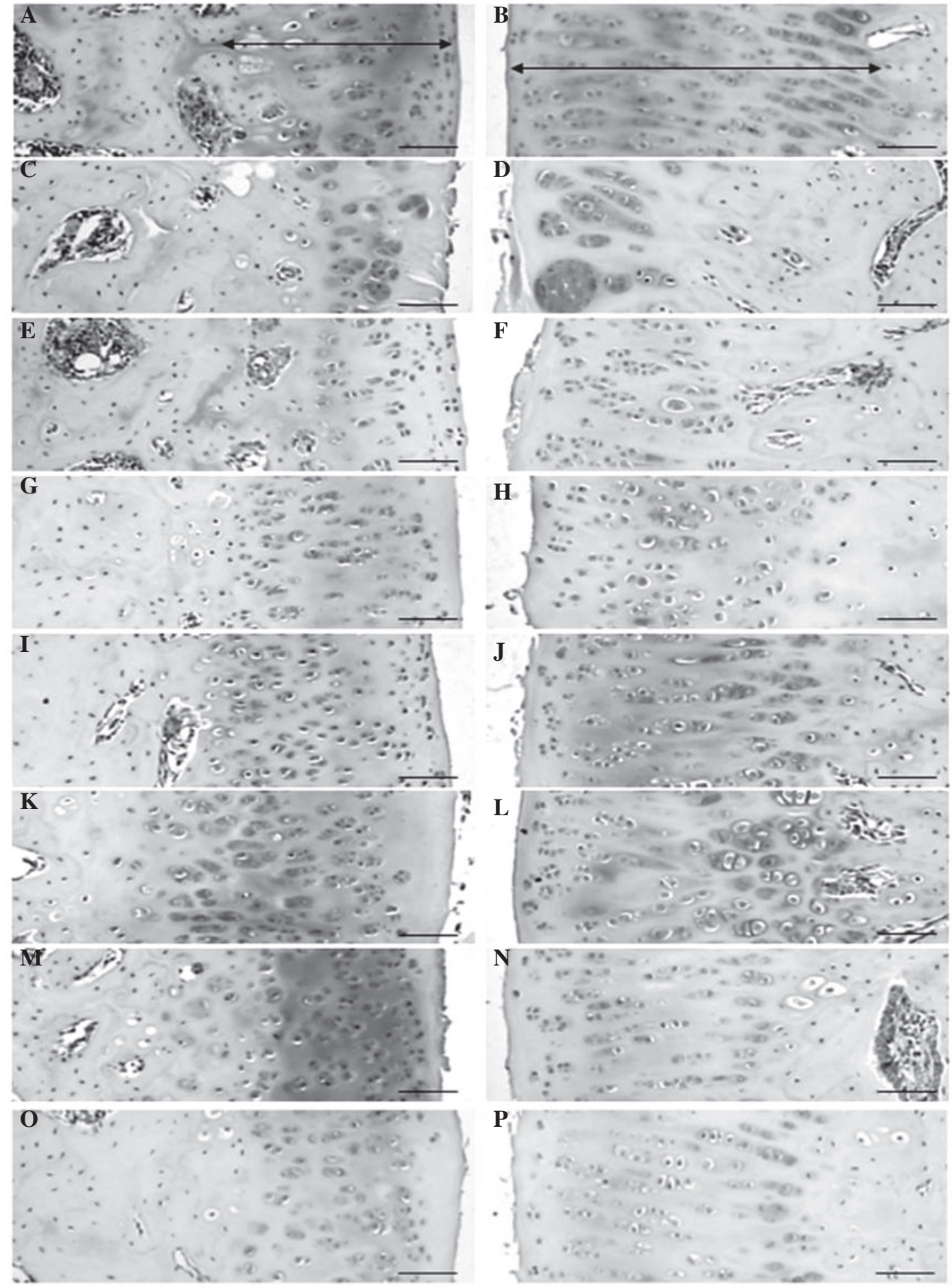

Figure 2. Histopathological observations in the articular surface cartilage of the femur and tibia of the (A and B) sham control, (C and D) OA control, (E and F) diclofenac sodium, (G and H) Polycan alone, (I and J) Ca LG alone and polycalcium at (K and L) 200, (M and N) 100 and $(\mathrm{O}$ and $\mathrm{P}) 50 \mathrm{mg} / \mathrm{kg}$ groups. Note that the articular surface of the femur was markedly damaged (based on the Mankin scoring system, which showed abnormal changes on the surface, hypocellularity, multiple clones and reductions in Safranin O staining intensity) in the OA control with reductions in cartilage thickness compared with the sham control. However, this femur damage was markedly inhibited by all test materials. The polycalcium $(50 \mathrm{mg} / \mathrm{kg}$ )-treated group showed a similar inhibition of articular histopathological damage as the Ca LG (100 mg/kg)-treated group. Polycan alone showed the least favorable effects on articular histopathological damage. OA, osteoarthritis; Ca, calcium; LG, lactate-gluconate. Arrows indicate the thickness of the articular cartilages. All Safranin O stained. Scale bars $=160 \mu \mathrm{m}$.

Changes in BrdU uptake. Significant $(\mathrm{P}<0.01)$ reductions in the numbers of BrdU-immunoreactive cells were detected in the inner articular membrane and the articular cartilage of the tibia and femur of the OA control group compared with the those in sham control group. However, these reductions in BrdU-immunoreactive cell numbers were signifi- 

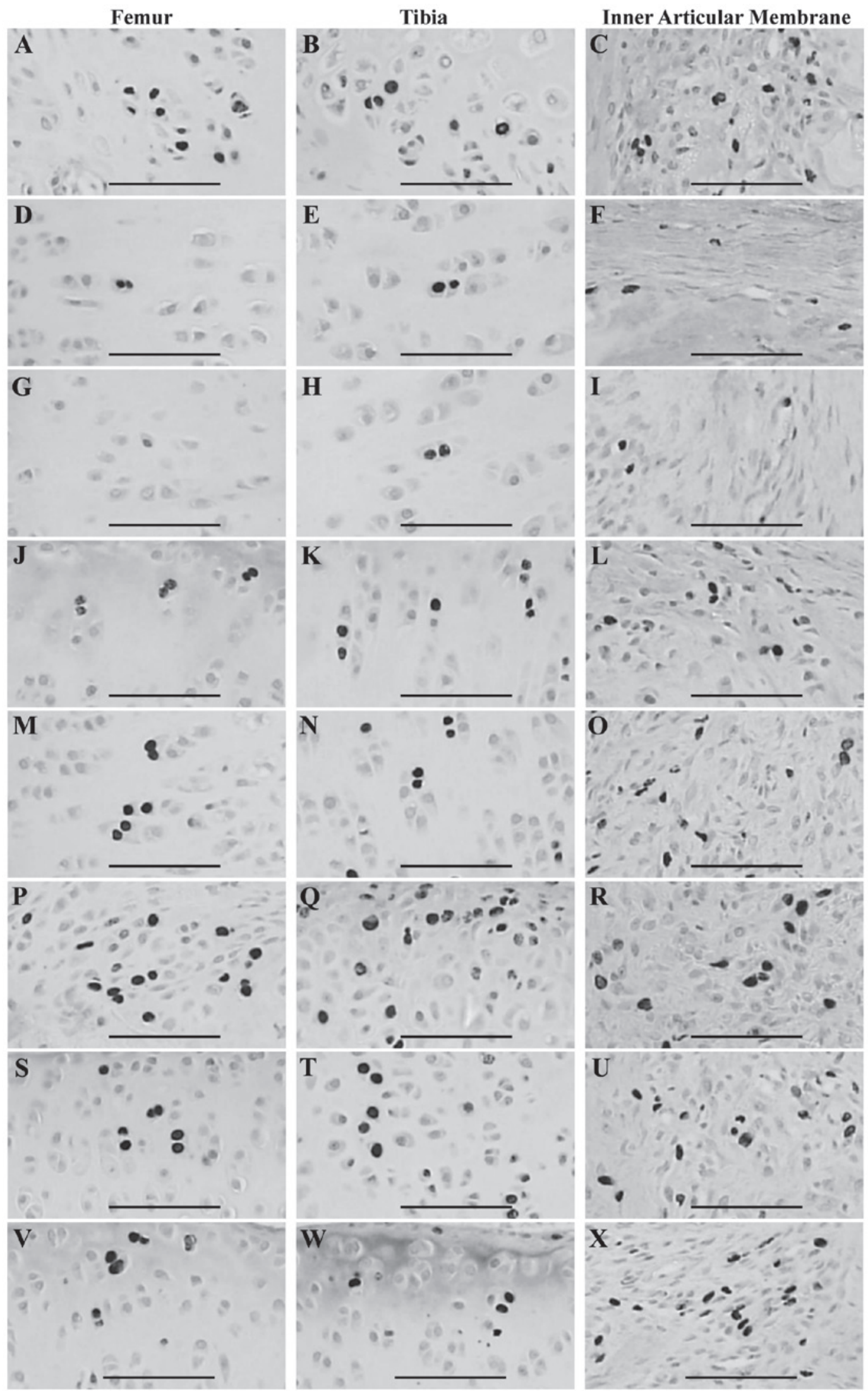

Figure 3. BrdU-immunoreactive cells detected in the articular surface cartilage of the femur and tibia and the inner articular membranes in the (A-C) sham control, (D-F) OA control, (G-I) diclofenac sodium, (J-L), Polycan alone, (M-O) Ca LG alone and polycalcium at (P-R) 200, (S-U) 100 and (V-X) $50 \mathrm{mg} / \mathrm{kg}$ groups. Note that similar numbers of BrdU-immunoreactive cells were detected in the articular cartilage of the femur and tibia and inner articular membrane of the OA control compared with the sham control. However, these reductions in BrdU-immunoreactive cells were significantly $(\mathrm{P}<0.01)$ inhibited by all test materials, with the exception of diclofenac sodium, in which the BrdU immunoreactivities detected in the inner articular membrane and both femur and tibia were similar to those in the OA control. The polycalcium $(50 \mathrm{mg} / \mathrm{kg})$-treated group showed a similar inhibitory effect on the reductions in BrdU immunoreactivity to those in the group treated with Ca LG alone $(100 \mathrm{mg} / \mathrm{kg})$. Polycan alone showed the least significant reversal of the reduction in BrdU immunoreactivity. OA, osteoarthritis; Ca, calcium; LG, lactate-gluconate. All processed by avidin biotin peroxidase complex (ABC) methods. Scale bars $=160 \mu \mathrm{m}$. 
cantly $(\mathrm{P}<0.01)$ inhibited by treatment with test materials, with the exception of diclofenac sodium; the BrdU immunoreactivities detected in the inner articular membrane, femur and tibia of the diclofenac sodium-treated group were similar to those observed in the OA control. The Polycalcium $(50 \mathrm{mg} / \mathrm{kg})$-treated group exhibited a reversal of the reduction in BrdU immunoreactivity similar to that in the group treated with $\mathrm{Ca}$ lactate-gluconate alone. Polycan alone resulted in the least significant reversal in the reduction in BrdU immunoreactivity (Table VI, Fig 3).

The numbers of BrdU-immunoreactive cells in the articular cartilage of the femur in the OA control were decreased by $79.68 \%$ compared with those in the sham control. Increases of $2.63,89.47,150.00,368.42,260.53$ and $184.21 \%$ were observed following treatment with diclofenac sodium, Polycan alone, $\mathrm{Ca}$ lactate-gluconate alone or Polycalcium $(50,100$ and $200 \mathrm{mg} / \mathrm{kg}$ ), respectively, compared with the BrdU-immunoreactive cell numbers in the OA control.

The BrdU-immunoreactive cell numbers in the articular cartilage of the tibia of the OA control were decreased by $77.97 \%$ compared with those in the sham control. Increases in BrdU-immunoreactive cell numbers of 0.70, 95.80, 121.68, 261.54,209.79 and $130.07 \%$ were observed following treatment with diclofenac sodium, Polycan alone, Ca lactate-gluconate alone and Polycalcium (50, 100 and $200 \mathrm{mg} / \mathrm{kg})$, respectively, compared with those in the OA control.

The BrdU-immunoreactive cell numbers in the inner articular membranes of the OA control were decreased by $74.14 \%$ compared with those in the sham control. Increases of $1.92,69.23,111.54,413.46,346.15$ and $148.08 \%$ were observed following treatment with diclofenac sodium, Polycan alone, Ca lactate-gluconate alone and Polycalcium (50, 100 and $200 \mathrm{mg} / \mathrm{kg}$ ), respectively, compared with the BrdU-immunoreactive cell numbers in the OA control.

\section{Discussion}

Osteoarthritis (OA) is a progressive rheumatic disease in which the articular cartilage degenerates. It is the most common rheumatic disorder and is likely to become one of the most prevalent and costly diseases (30). Paracetamol may be used as a drug therapy for OA, alone or in combination with codeine. Topical and oral NSAIDs, such as diclofenac and ibuprofen, are also used to mitigate pain and improve function in patients with OA $(2,3)$. However, the dose and duration of treatment with oral NSAIDs should be minimized to reduce the risk of associated morbidities, such as cardiovascular, gastrointestinal, liver or renal complications (31). Therefore, there is a requirement for drugs with good efficacy and low toxicity to treat OA.

In a previous study, Polycalcium, which comprises a mixture of Polycan and Ca lactate-gluconate in a 1:9 ratio by weight, showed the most favorable and synergistic effects on osteoporotic rats among three Polycan and Ca lactate-gluconate mixtures (1:99, 5:95 and $10: 90$ by weight) (18). In the present study, the beneficial effects of Polycalcium on OA were confirmed in comparison with Polycan and Ca lactate-gluconate alone.

In the present study, no significant changes in body weight were detected in the test material-treated groups compared with the OA control.
$\mathrm{OA}$ is a degenerative joint disease and a chronic inflammatory condition. Cartilage damage in OA can lead to edematous changes in the surrounding tissues and increases in the thickness of affected joints (32). The thickness of the operated knees increased significantly in the present study. However, the surgery-induced changes in knee thickness were reversed by the test materials. The Polycalcium-treated group showed more favorable inhibitory effects on the increases in knee thickness, regardless of capsule exposure, compared with those in the groups treated with Polycan or Ca lactate-gluconate alone. The Polycalcium $(50 \mathrm{mg} / \mathrm{kg}$ )-treated group demonstrated a similar reversal of the increase in knee thickness to that observed in the group treated with Ca lactate-gluconate alone. Polycan alone showed the least significant reduction in knee thickness. These favorable effects on knee thickness may be due to the anti-inflammatory properties of Polycan $(14,15)$ and/or Ca salts $(6,7)$, as described previously. These results demonstrate that appropriate mixtures of Polycan and $\mathrm{Ca}$ lactate-gluconate are able to induce favorable synergistic anti-inflammatory effects in OA rats.

Anterior cruciate ligament transection and partial medial meniscectomy increases the maximum extension angles (limited extension values), causes edematous changes in the knees and capsule thickness, and decreases chondrocyte proliferation (detected by BrdU uptake) and the levels of cartilage GAGs (chondroitin sulfate, heparan sulfate and hyaluronic acid). It also causes marked degenerative changes in the cartilage, affect the Mankin score and reduce articular cartilage, which are classic symptoms of osteoarthritis.

However, these OA-associated changes were inhibited after 28 days of continuous oral treatment with three doses of Polycalcium compared with the OA control. Favorable anti-OA effects were detected in Polycalcium-treated rats compared with those in rats treated with Polycan and Ca lactate-gluconate alone. Additionally, Polycalcium (50 mg/kg) showed favorable effects similar to those of Ca lactate-gluconate $(100 \mathrm{mg} / \mathrm{kg})$ alone.

Fibrosis in $\mathrm{OA}$ is the result of chronic inflammatory processes that limit joint motion; joint stiffness is a major symptom of OA. Joint stiffness has been evaluated using the maximum extension angle of the joint, considering $0^{\circ}$ as the maximum extension, with lower values representing better knee function (19). Increases in maximum extension angles in the knees were inhibited by all test materials, suggesting that they are able to ameliorate OA.

Although diclofenac sodium did not affect BrdU uptake, the number of BrdU-immunoreactive cells increased following treatment with Polycalcium, suggesting that Polycalcium induces the proliferation of chondrocytes in the inner articular membranes and surface articular cartilage of the tibia and femur. In addition, higher BrdU-immunoreactivities were detected in Polycalcium-treated rats than in rats treated with Polycan and Ca lactate-gluconate; Polycalcium (50 mg/kg) showed BrdU-immunoreactivities similar to those of Ca lactate-gluconate alone in rats in the present study.

As OA progresses, the loss of various components of the extracellular cartilage matrix, particularly GAGs, has been reported (33). Extracellular cartilage matrix contains sulfide proteoglycans such as chondroitin sulfate, heparin sulfate, keratin sulfate and dermatan sulfate (34), and changes in 
sulfide proteoglycans in cartilage or blood have been used as markers of OA progression because they are released from damaged cartilage to the blood during OA (35). In addition, hyaluronic acid is a relatively large polysaccharide secreted by type $\mathrm{B}$ synoviocytes in the joints. Therefore, a reduction in the hyaluronic acid content of cartilage is a useful marker of OA (36). In the present study, the cartilage GAG levels of the operated knees decreased significantly. However, these changes in cartilage GAGs were reduced by treatment with the test materials. The Polycalcium-treated group showed inhibitory effects on the reductions in cartilage GAG content that were more favorable than those in the groups treated with Polycan or $\mathrm{Ca}$ lactate-gluconate alone, and the Polycalcium (50 mg/kg)-treated group exhibited inhibitory effects on the reductions in cartilage GAG content similar to those in the group treated with $\mathrm{Ca}$ lactate-gluconate alone. Polycan alone showed the least significant beneficial effects on cartilage GAG content.

The Mankin scoring system is a common histopathological evaluation method used to detect articular cartilage injuries. In this system, the higher the score, the higher the level of OA $(19,24)$. Favorable reductions in the Mankin score were observed following treatment with the test materials in the present study; thus, the test materials ameliorated OA. Marked reductions in articular cartilage thickness in OA have been reported (27). In the present study, all test materials effectively inhibited reductions in articular cartilage thickness. The Polycalcium-treated group showed more favorable inhibition effects on the increases in Mankin scores and cartilage loss compared with those in the groups treated with Polycan or Ca lactate-gluconate alone, and the Polycalcium $(50 \mathrm{mg} / \mathrm{kg})$-treated group exhibited similar inhibition effects on the increases in Mankin score and cartilage loss to those observed in the group treated with Ca lactate-gluconate alone. Polycan alone showed the least significant reductions in Mankin score and cartilage preservation.

Among the various methods of detecting cell proliferation in histological sections, immunohistochemistry for BrdU is preferable $(27,37)$. BrdU staining is easier to interpret and reflects the cell proliferation more specifically than other staining (26). In addition, BrdU uptake can be used to detect chondrocyte proliferation in OA-affected cartilage (27). Cells containing BrdU represent proliferated or proliferating cells. In the present study, the number of BrdU-immunoreactive cells decreased significantly in the inner articular membrane and surface articular cartilage of the femur and tibia in the OA control, suggesting that the proliferation of chondrocytes was inhibited significantly. Although diclofenac sodium did not affect BrdU uptake, BrdU-immunoreactive cells increased following treatment with all three doses of Polycalcium, suggesting that Polycalcium induces the proliferation of chondrocytes in the inner articular membranes and surface articular cartilage of the tibia and femur. In addition, higher BrdU-immunoreactivity was detected in Polycalcium-treated rats than was detected in rats treated with Polycan and Ca lactate-gluconate alone; Polycalcium (50 mg/kg) showed BrdU-immunoreactivities comparable with those of Ca lactate-gluconate alone $(100 \mathrm{mg} / \mathrm{kg})$ in the present study. The cartilage proliferative effects of Polycan (16) and Ca salts (17) have been reported previously.

The results obtained in this study suggest that 28-day continuous oral treatment with Polycalcium reduces articular stiffness and histological cartilage damage compared with that in OA controls, and may induce chondrocyte proliferation based on BrdU uptake. More favorable anti-OA effects based on chondrocyte proliferation were detected in Polycalcium-treated rats than were detected in rats treated with Polycan or $\mathrm{Ca}$ lactate-gluconate alone; Polycalcium $(50 \mathrm{mg} / \mathrm{kg})$ showed favorable effects on OA similar to those of Ca lactate-gluconate alone $(100 \mathrm{mg} / \mathrm{kg})$. Therefore, a mixture of Polycan and Ca lactate-gluconate exhibited favorable synergistic anti-OA effects.

\section{References}

1. De Silva V, El-Metwally A, Ernst E, et al; Arthritis Research UK Working Group on Complementary and Alternative Medicines: Evidence for the efficacy of complementary and alternative medicines in the management of osteoarthritis: a systematic review. Rheumatology (Oxford) 50: 911-920, 2011.

2. Long L, Soeken K and Ernst E: Herbal medicines for the treatment of osteoarthritis: a systematic review. Rheumatology (Oxford) 40: 779-793, 2001.

3. Walker J: Management of osteoarthritis. Nurs Older People 23: 14-19, 2011.

4. Buchanan WW: Implications of NSAID therapy in elderly patients. J Rheumatol Suppl 20: 29-32, 1990.

5. Tramèr MR, Moore RA, Reynolds DJ and McQuay HJ: Quantitative estimation of rare adverse events which follow a biological progression: a new model applied to chronic NSAID use. Pain 85: 169-182, 2000.

6. Piller NB: Assessment of anti-inflammatory activity of calcium dobesilate. Effect on macrophages attaching to subcutaneously implanted cover slips in guinea pigs. Arznemittelforchung 40: 698-700, 1990

7. Smith MM, Ghosh P, Numata Y and Bansal MK: The effects of orally administered calcium pentosan polysulfate on inflammation and cartilage degradation produced in rabbit joints by intraarticular injection of a hyaluronate-polylysine complex. Arthritis Rheum 37: 125-136, 1994.

8. Sosa M and Bregni C: Metabolism of the calcium and bioavailability of the salts of most frequent use. Boll Chim Farm 142: 28-33, 2003.

9. Heaney RP, Recker RR, Watson P and Lappe JM: Phosphate and carbonate salts of calcium support robust bone building in osteoporosis. Am J Clin Nutr 92: 101-105, 2010.

10. Seo HP, Kim JM, Shin HD, Kim TK, Chang HJ, Park BR and Lee JW: Production of $\beta-1,3 / 1,6$-glucan by Aureobasidium pullulans SM-2001. Korean Journal of Biotechnology and Bioengineering 17: 376-380, 2002 (In Korean).

11. Song HB, Park DC, Do GM, Hwang SL, Lee WK, Kang HS, Park BR, Jang HJ, Son CW, Park EK, Kim SY and Huh TL: Effect of exopolymers of Aureobasidium pullulans on improving osteoporosis induced in ovariectomized mice. J Microbiol Biotechnol 16: 37-45, 2006.

12. Shin HD, Yang KJ, Park BR, Son CW, Jang HJ and Ku SK: Antiosteoporotic effect of Polycan, beta-glucan from Aureobasidium, in ovariectomized osteoporotic mice. Nutrition 23: 853-860, 2007.

13. Lee HS, Cho HR, Moon SB, Shin HD, Yang KJ, Park BR, Jang HJ, Kim LS and Ku SK: Effect of $\beta$-glucan from Aureobasidium pullulans on rat rib fracture healing. Lab Anim Res 24: 39-44, 2008.

14. Kim HD, Cho HR, Moon SB, Shin HD, Yang KJ, Park BR, Jang HJ, Kim LS, Lee HS and Ku SK: Effect of exopolymers from Aureobasidum pullulans on formalin-induced chronic paw inflammation in mice. J Microbiol Biotechnol 16: 1954-1960, 2006.

15. Kim HD, Cho HR, Moon SB, Shin HD, Yang KJ, Park BR, Jang HJ, Kim LS, Lee HS and Ku SK: Effects of $\beta$-glucan from Aureobasidum pullulans on acute inflammation in mice. Arch Pharm Res 30: 323-328, 2007.

16. Kim JW, Cho HR and Ku SK: Efficacy test of Polycan, a geta-glucan originated from Aureobasidium pullulans SM-2001, on anterior cruciate ligament transection and partial medial meniscectomy-induced-osteoarthritis Rats. J Microbiol Biotechnol 22: 274-282, 2012. 
17. Kang SJ, Kim JW, Kim KY, Ku SK and Lee YJ: Protective effects of calcium gluconate on osteoarthritis induced by anterior cruciate ligament transection and partial medial meniscectomy in Sprague-Dawley rats. J Orthop Surg Res 9: 14, 2014.

18. Choi JS, Kim JW, Kim KY, Cho HR, Choi IS and Ku SK: Anti-osteoporotic effects of Polycan in combination with calcium lactate-gluconate in ovariectomized rats. Exp Ther Med 8: 957-967, 2014.

19. Rezende MU, Gurgel HM, Vilaça Junior PR, et al: Diacerhein versus glucosamine in a rat model of osteoarthritis. Clinics (Sao Paulo) 61: 461-466, 2006

20. Homer KA, Denbow L and Beighton D: Spectrophotometric method for the assay of glycosaminoglycans and glycosaminoglycan-depolymerizing enzymes. Anal Biochem 214: 435-441, 1993.

21. Camplejohn KL and Allard SA: Limitations of safranin ' $O$ ' staining in proteoglycan-depleted cartilage demonstrated with monoclonal antibodies. Histochemistry 89: 185-188, 1988.

22. Kahveci Z, Minbay FZ and Cavusoglu L: Safranin O staining using a microwave oven. Biotech Histochem 75: 264-268, 2000.

23. Tran D, Golick M, Rabinovitz H, Rivlin D, Elgart G and Nordlow B: Hematoxylin and safranin $\mathrm{O}$ staining of frozen sections. Dermatol Surg 26: 197-199, 2000.

24. Armstrong S, Read R and Ghosh P: The effects of intraarticular hyaluronan on cartilage and subchondral bone changes in an ovine model of early osteoarthritis. J Rheumatol 21: 680-688, 1994.

25. Lovász G, Park SH, Ebramzadeh E, Benya PD, et al: Characteristics of degeneration in an unstable knee with a coronal surface step-off. J Bone Joint Surg Br 83: 428-436, 2001.

26. Hwang YI, Yoo YB and Baik SH: Comparative study of rat thyroid regeneration using PCNA and BrdU immunohistochemistry. Korean J Anat 33: 247-254, 2000.

27. Moore EE, Bendele AM, Thompson DL, Littau A, Waggie KS Reardon B and Ellsworth JL: Fibroblast growth factor-18 stimulates chondrogenesis and cartilage repair in a rat model of injury-induced osteoarthritis. Osteoarthritis Cartilage 13: 623-631, 2005.
28. Ito T, Mitui H, Udaka N, Hayashi H, Okudela K, Kanisawa M and Kitamura H: Ki-67 (MIB 5) immunostaining of mouse lung tumors induced by 4-nitroquinoline 1-oxide. Histochem Cell Biol 110: 589-593, 1998.

29. Tang X, Falls DL, Li X, Lane T and Luskin MB: Antigen-retrieval procedure for bromodeoxyuridine immunolabeling with concurrent labeling of nuclear DNA and antigens damaged by $\mathrm{HCl}$ pretreatment. J Neurosci 27: 5837-5844, 2007.

30. Brooks PM and March LA: New insights into osteoarthritis. Med J Aust 163: 367-369, 1995.

31. National Institute for Health and Clinical Excellence: COX II Inhibitors for the Treatment of Osteoarthritis and Rheumatoid Arthritis. NICE Technology Appraisal TA27. 2001.

32. Guo JS, Ou L, Zhou J, Wang XJ and Guo X: Impact on the model of rat osteoarthritis of jingu tablet. Zhongguo Zhong Yao Za Zhi 31: 232-235, 2006 (In Chinese).

33. Reddy GK and Dhar SC: Metabolism of glycosaminoglycans in tissues of adjuvant arthritic rat. Mol Cell Biochem 106: 117-124, 1991.

34. Haraoui B, Thonar EJ, Martel-Pelletier J, Goulet JR, Raynauld JP, Ouellet M and Pelletier JP: Serum keratan sulfate levels in rheumatoid arthritis: inverse correlation with radiographic staging. J Rheumatol 21: 813-817, 1994.

35. Thonar EJ, Lenz ME, Klintworth GK, Caterson B, Pachman LM, Glickman P, Katz R, Huff J and Kuettner KE: Quantification of keratan sulfate in blood as a marker of cartilage catabolism. Arthritis Rheum 28: 1367-1376, 1985.

36. Emlen W, Niebur J, Flanders G and Rutledge J: Measurement of serum hyaluronic acid in patients with rheumatoid arthritis: correlation with disease activity. J Rheumatol 23: 974-978, 1996.

37. Ganey T, Libera J, Moos V, Alasevic O, Fritsch KG, Meisel HJ and Hutton WC: Disc chondrocyte transplantation in a canine model: a treatment for degenerated or damaged intervertebral disc. Spine (Phila Pa 1976) 28: 2609-2620, 2003. 